\title{
Roller Straightening Process and FEM Simulation for Stainless Steel Clad Plate
}

\author{
Jin He-Rong ${ }^{1,2}$, Yi Ya-Li ${ }^{*}, 3$, Han Xue-Yan ${ }^{3}$ and Liang Yan ${ }^{3}$ \\ ${ }^{I}$ Key Laboratory of Advanced Forging \& Stamping Technology and Science of Ministry of National Education, Yanshan \\ University, Qinhuangdao, 066004, China \\ ${ }^{2}$ Parallel Robot and Mechatronic System Laboratory of Hebei Province, Yanshan University, Qinhuangdao, 066004, \\ China \\ ${ }^{3}$ School of Mechanical Engineering, Yanshan University, Qinhuangdao, 066004, China
}

\begin{abstract}
Based on elasto-plastic deformation straightening theory and by adopting 11 rolls straightening plates, the isothermal residual curvature straightening process was proposed for stainless steel clad plate. The mathematical model of straightening was established to realize plate shape finishing and stress reforming. By using finite element analysis software, establishing straightening process and determining intermesh, the effects of intermesh on shape and residual stress were analyzed. The results indicate that the straightening process met the finishing plainness of stainless steel clad plate after rolling. Longitudinal residual stress of the clad plate was evenly distributed across width. The cladding plate and steel substrate were observed to be symmetrical and the ascent of stress near the edge was greater. Longitudinal residual stress across length was distributed with the wave of pull-press-pull and the cladding plate and base plate were observed to be symmetrical. The above researches are based on the previous theory of the application of stainless steel clad plate straightening technology.
\end{abstract}

Keywords: FEM analysis, intermesh, residual stress, roller straightening, stainless steel clad plate.

\section{INTRODUCTION}

Complying with the overall national planning for building a resource-saving and environment-friendly green steel industry, stainless steel clad plate combines high corrosion resistance of stainless steel and excellent mechanical properties of low-alloy steel, mainly used in petrochemical, marine engineering, nuclear and high-quality oil and gas pipelines and other major equipment industry $[1$, 2]. Because of different deformation resistance and thermal expansion coefficients of stainless steel cladding plate and steel substrate, the hot-rolled stainless steel clad plate shows great bending deformation and residual stress to the side of cladding plate after rolling. This defect is difficult to eliminate in the cold state and greatly influences the shape and quality [3].

Parallel roller leveler can straighten the plate with different original curvature even after repeated bending, reduce the residual stress and make it homogenized [4]. In the roller straightening process, a suitable intermesh is the key to ensure the quality of straightening. Presently, a lot of researches have been done on bending deflection model and reduction pattern of roller straightening of plate [5-7]. With the development of finite element theory, simulating the plate straightening process by finite element analysis software can accurately forecast the law of straightening [810]. However, the research for stainless steel clad plate

*Address correspondence to this author at the School of Mechanical Engineering, Yanshan University, Qinhuangdao, 066004, China;

Tel: +8613933603018; Fax: +863358065296; E-mail: yiyali@ysu.edu.cn straightening technology is rare. In this paper, for the problem of hot-rolled stainless steel clad plate straightening, based on the elasto-plastic straightening theory, the isothermal residual curvature straightening process is given. Explicit dynamic finite element analysis software ANSYS/LS-DYNA was used to simulate roller-straightening process and analyze the effect of straightening process parameters on straightening quality, which provided some guidance for the production practices of stainless steel clad plate.

\section{MODEL OF STRAIGHTENING PROCESS}

Bending deflection is an important parameter in the straightening model. In engineering applications, material mechanics methods are commonly used to calculate the deflection [4]. At the deflection state of Fig. (1), according to the plane section assumption, without considering shear deformation, bending deflection $\delta w$ is

$\delta_{\mathrm{w}}=\int_{0}^{l} x A_{\Sigma \mathrm{x}} \mathrm{d} x-\delta_{0}$

where, $x$ is the distance to the side straightening roller $(\mathrm{mm})$; $A_{\sum x}$ is the total bending curvature at $\mathrm{x}(1 / \mathrm{mm})$; and $\delta_{0}$ is the original bending deflection $(\mathrm{mm})$.

When the bending moment $M$ that is applied to stainless steel clad plate is removed, an equivalent resilient rebound effect caused by the bending moment $-M$ is produced. The springback curvature $A_{f}$ can be obtained by the following formula 


$$
M=\frac{1}{3} A_{\mathrm{f}} B\left\{E_{2}\left[z_{2}^{3}+\left(z_{1}-h_{1}\right)^{3}\right]+E_{1}\left[z_{1}^{3}-\left(z_{1}-h_{1}\right)^{3}\right]\right\}
$$

where, $E_{1}$ and $E_{2}$ represent the elastic modulus of the cladding plate and substrate, respectively $(\mathrm{MPa})$.

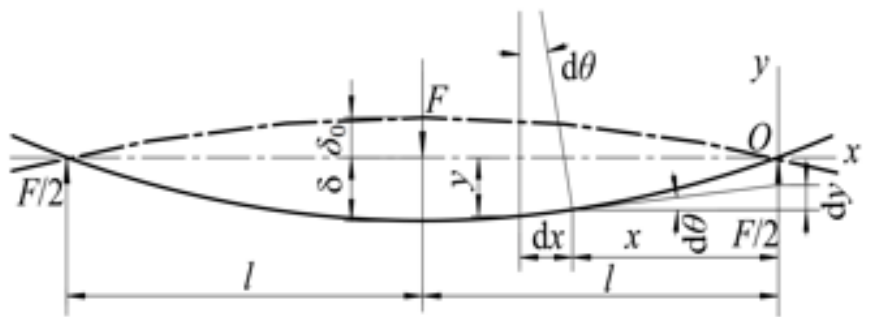

Fig. (1). The midpoint bending deflection.

After unloading, the bending deflection of stainless steel clad plate resumes. After resuming, the residual deflection is $\delta_{c}$, and elastic recovery deflection $\delta_{f}$ is

$\delta_{\mathrm{f}}=\int_{0}^{l} x A_{\mathrm{fx}} \mathrm{d} x$

where, $A_{f x}$ is the elastic recovery curvature at $x(1 / \mathrm{mm})$.

Therefore, the residual deflection $\delta_{c}$ is

$\delta_{\mathrm{c}}=\delta_{\mathrm{w}}-\delta_{\mathrm{f}}=\int_{0}^{l} x A_{\Sigma \mathrm{x}} \mathrm{d} x-\delta_{0}-\delta_{\mathrm{f}}$

where, $A_{f x}$ is the elastic recovery curvature at $x(1 / \mathrm{mm})$.

\section{STRAIGHTENING PROCESS SCHEME}

The temperature of hot-straightening is generally between $500^{\circ} \mathrm{C}$ and $800^{\circ} \mathrm{C}$, and at the same temperature, thermal expansion coefficient of stainless steel cladding plate $\boldsymbol{\alpha}_{1}$ is greater than that of carbon steel substrate $\boldsymbol{\alpha}_{2}$. As a result, in the cooling process, the contraction length of stainless steel cladding plate is larger than that of the carbon steel substrate, resulting in longitudinal bending to the side of cladding plate. In view of this phenomenon, isothermal residual curvature straightening process plan is made, that is, in the hot-straightening process, the temperature of two base metals of stainless steel clad plate is kept consistent. As a result, at the end of the straightening process, the stainless steel clad plate have some residual curvature bending to a substrate side. When the temperature decreases to room temperature, the difference in thermal expansion coefficient of the two base metals keeps the clad plate into a straight state.

The shape changes of stainless steel clad plate before and after cooling, are shown in Fig. (2). $l$ is the length of the clad plate when the clad plate was cooled down to room temperature, $h_{1}$ and $h_{2}$ are the thickness of cladding plate and substrate respectively, $l_{l}$ and $l_{2}$ are the lengths of cladding plate and substrate after hot-straightening respectively. Considering that the thermal expansion and cold contraction of the steel is a reversible process, the clad plate, which is straight at room temperature, is heated to temperature of the hot-straightening process. Following this, the clad plate generates longitudinal bending toward the substrate side, which is the reversible process as shown in Fig. (2). The following is the derivation of bending curvature heated at room temperature by the hot-straightening temperature process.
Assuming that the longitudinal bending of stainless steel clad plate is a circular-arc, the average curvature radius located at the half of the thickness of the cladding and substrate plate is $R_{l}$ and $R_{2}$ respectively, which is

$\frac{l_{1}}{l_{2}}=\frac{R_{1}}{R_{2}}$

As Fig. (2) shows

$R_{1}-R_{2}=\frac{1}{2}\left(h_{1}+h_{2}\right)$

(a) Plate shape after hot-straightening

(b) Plate shape at room temperature

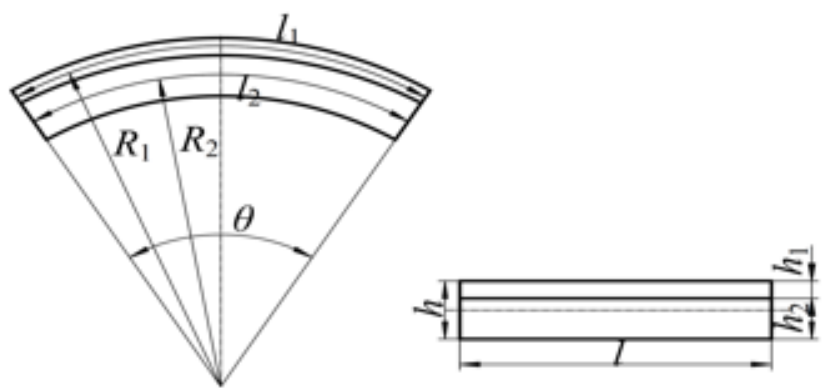

Fig. (2). Plate shape before and after cooling.

The shortened length $\Delta l_{1}$, due to the effect of the compressive stress by the substrate can be obtained according to Hooke Law as:

$\Delta l_{1}=l\left(\alpha_{1}-\alpha_{2}\right) \Delta t \frac{E_{2} S_{2}}{E_{1} S_{1}+E_{2} S_{2}}$

where, $S_{1}$ and $S_{2}$ are the section area of cladding plate and base plate, respectively $\left(\mathrm{mm}^{2}\right)$.

Combining the equations (5), (6) and (7), under the same width of stainless steel clad plate $B$, section area $S=B h$ is proportional to the thickness $h$, and $R_{2}$ is given by

$R_{2}=\frac{\left(h_{1}+h_{2}\right)\left(E_{1} h_{1}+E_{2} h_{2}\right)}{2 E_{1} h_{1}\left(\alpha_{1}-\alpha_{2}\right) \Delta t}$

After straightening and taking the bending radius of the thickness center of stainless steel clad plate as the residual curvature radius $R$, we obtain:

$R=\frac{1}{2} h_{1}+R_{2}=\frac{\left(h_{1}+h_{2}\right)\left(E_{1} h_{1}+E_{2} h_{2}\right)}{2 E_{1} h_{1}\left(\alpha_{1}-\alpha_{2}\right) \Delta t}+\frac{1}{2} h_{1}$

Using 11 medium rolls and heavy plate leveler, a bending calculation is carried out, as shown in Fig. (3). The basic parameters of roll leveler are shown in Table 1.

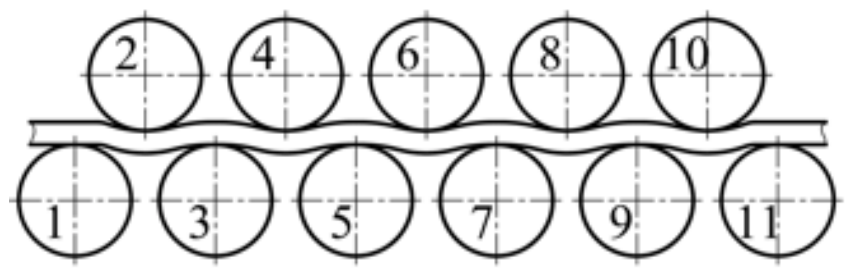

Fig. (3). Structure diagram of roller straightening model. 
The material property of stainless steel clad plate is shown in Table 2 [11].

Table 1. Parameters of straightening machine.

\begin{tabular}{|c|c|c|c|}
\hline $\begin{array}{c}\text { Roll } \\
\text { Diameter/mm }\end{array}$ & $\begin{array}{c}\text { Roller } \\
\text { Spacing/mm }\end{array}$ & $\begin{array}{c}\text { Roll } \\
\text { Length/mm }\end{array}$ & $\begin{array}{c}\text { Arrangement } \\
\text { of Roller System }\end{array}$ \\
\hline \hline 285 & 300 & 3500 & $\begin{array}{c}\text { Above 5 rollers } \\
\text { Below 6 rollers }\end{array}$ \\
\hline
\end{tabular}

Table 2. Material property of stainless steel clad plate.

\begin{tabular}{|c|c|c|}
\hline Parameters & Cladding Plate 316L & Substrate Q345R \\
\hline \hline Density $/\left(\mathrm{kg} / \mathrm{m}^{3}\right)$ & 8000 & 7850 \\
\hline Elastic modulus/GPa & 151 & 125 \\
\hline Yield strength $/ \mathrm{MPa}$ & 160 & 135 \\
\hline $\begin{array}{c}\text { Thermal expansion } \\
\text { coefficient } /\left(10^{-6} /{ }^{\circ} \mathrm{C}\right)\end{array}$ & 18.71 & 14.62 \\
\hline Poisson's ratio & 0.3 & 0.3 \\
\hline $\begin{array}{c}\text { Length } \times \text { width } \times \\
\text { thickness } / \mathrm{mm}\end{array}$ & $5000 \times 3000 \times 5$ & $5000 \times 3000 \times 45$ \\
\hline
\end{tabular}

When setting the intermesh of straightening roller, the intermesh of the first four straightening rollers adopts small deformation straightening scheme to make the stainless steel clad plate flat, and the last intermesh gives the stainless steel clad plate a residual curvature for bending to the side of the cladding plate. Based on the parameters shown in Table $\mathbf{2}$, the intermeshes of straightening roller are obtained by calculation, as shown in Table 3.

Table 3. Material property of stainless steel clad plate.

\begin{tabular}{|c|c|c|}
\hline Roll No. & $\begin{array}{c}\text { Initial Curvature } \mathbf{0 . 1}^{-\mathbf{1}} \\
\text { The Intermesh }\end{array}$ & $\begin{array}{c}\text { Initial Curvature } \mathbf{0 . 2 ~}^{-\mathbf{1}} \\
\text { The Intermesh }\end{array}$ \\
\hline \hline 2 & 0.22 & 0.24 \\
\hline 4 & 0.186 & 0.189 \\
\hline 6 & 0.176 & 0.178 \\
\hline 8 & 0.172 & 0.175 \\
\hline 10 & 0.21 & 0.22 \\
\hline
\end{tabular}

\section{FINITE ELEMENT ANALYSIS AND DISCUSSION}

\subsection{Finite Element Model}

Taking the above-mentioned analysis data as the simulation object, the finite element model of roller straightening was established, as shown in Fig. (4).

Material property parameters of stainless steel clad plate are shown in Table 2, and basic parameters of roll leveler are shown in Table 1. Straightening temperature is $600^{\circ} \mathrm{C}$. Considering the role of the backup roll, the straightening roll was taken as a hollow rigid body. Eight nodes solid element was used to establish the bilinear kinematic hardening material model. Due to the special nature of the joint surface of clad plate, Glue Boolean operations were used for the joint surface of substrate and cladding plate before meshing, to ensure that the joint surface shares the nodes. For modeling using $1 / 2$ of the plate width, the unit was divided into $165 \times 50 \times(7$ base plates +3 cladding plates $)($ Length $\times$ width $\times$ thickness), 82,500 in all.

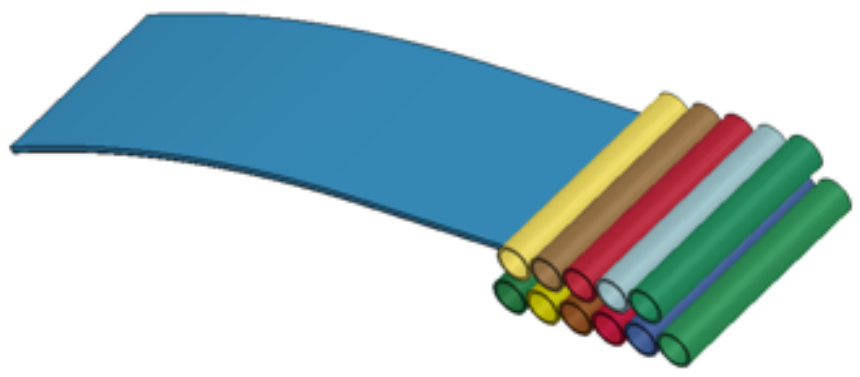

Fig. (4). FEM straightening model.

\subsection{The Residual Curvature Analysis after Straightening}

As the residual curvature of stainless steel clad plate becomes very small after straightening, it was assumed that the final shape of sheet is a circular arc, whose radius is equal to the radius of the residual curvature $R$. Reading the stainless steel clad plate coordinates after straightening, , the values of residual curvature radius were obtained, as shown in Table 4. The roughness values of plate can be calculated by the chord height of the $1000 \mathrm{~mm}$ chord length. According to the Chinese standard (GB/T8165-2008), the roughness values of stainless steel clad plate should be less than $10 \mathrm{~mm} / \mathrm{m}$. The higher standard for stainless steel clad plate is that the roughness values should be within $5 \mathrm{~mm} / \mathrm{m}$.

As can be seen from Table 4, after straightening, stainless steel clad plate bends to the substrate side, coinciding with the results of the process. With the increase of straightening speed or the original curvature, elastic-plastic deformation rate of stainless steel clad plate increased, suggesting that the material work hardening phenomenon is more obvious, resulting in simulation requiring intermesh greater than the theoretical amount. The value of residual curvature radius increased, and showed a certain bias compared with the theoretical calculation $89 \mathrm{~mm}$. Through calculation, the maximum roughness after straightening was $1.53 \mathrm{~mm} / \mathrm{m}$, and the minimum roughness was $0.64 \mathrm{~mm} / \mathrm{m}$. According to residual curvature straightening process with the temperature difference, along with the cooling after straightening, stainless steel clad plate producess shrinkage and deformation to the side of cladding plate, and the roughness values are further improved.

\subsection{The Residual Stress Analysis after Straightening}

Other studies have shown that the longitudinal residual stress of plate is the main residual stress after straightening and has the main influence on the plate shape [7]. Taking the surface path of stainless steel clad plate AA and BB as the research object, the longitudinal residual stress of stainless steel clad plate was analyzed after straightening, as shown in Fig. (5). 
The original curvature of a stainless steel clad plate was $0.1 \mathrm{~m}^{-1}$ and the straightening speed was $5 \mathrm{~m} / \mathrm{s}$. After straightening, the longitudinal stress distribution along the setting path on the substrate and cladding plate surface is, shown in Fig. (6) and Fig. (7), respectively.

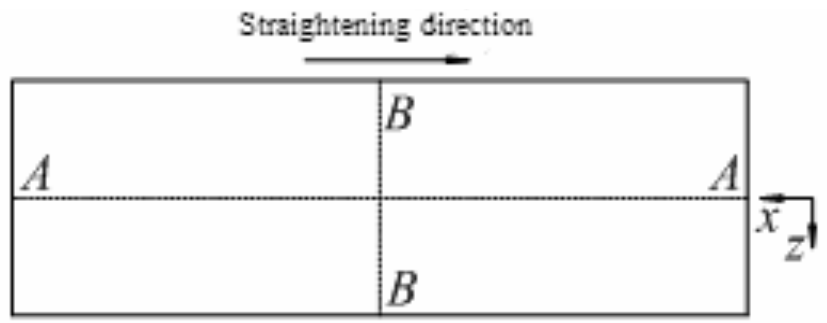

Fig. (5). The position of paths in the stainless steel clad plate.

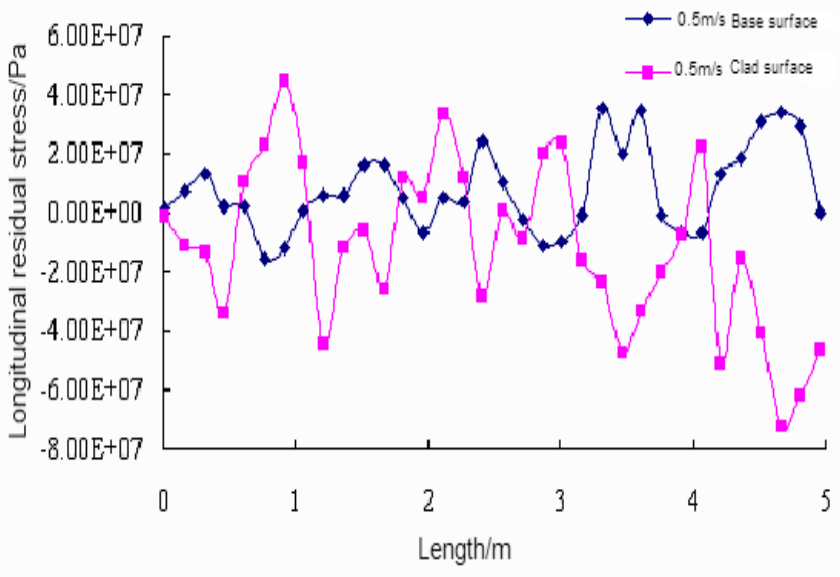

Fig. (6). Longitudinal residual stress path AA across length.

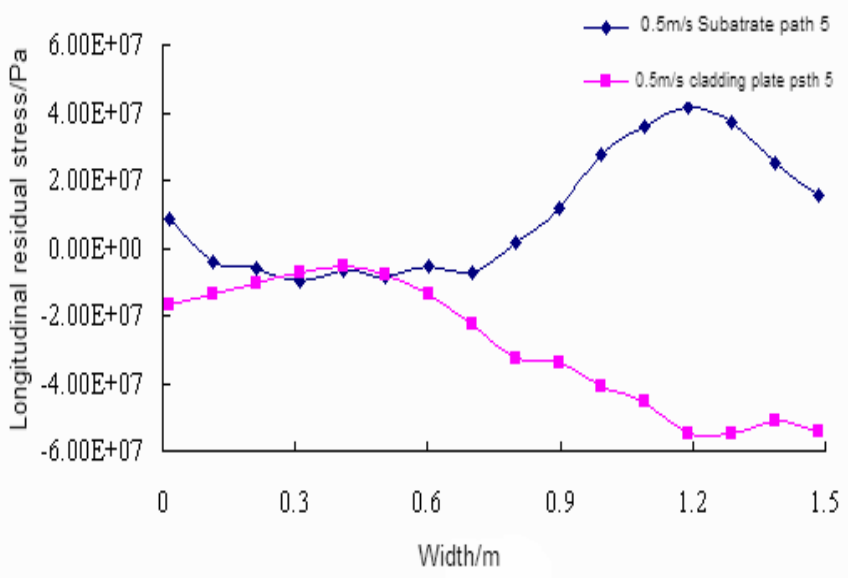

Fig. (7). Longitudinal residual stress path BB across width.

As shown in Fig. (6), the longitudinal residual stress along the length direction presented a tensile-compressiontensile wave distribution and the substrate side and the cladding side were observed to be symmetrical. Longitudinal residual stress distribution was more uniform before the tail, while the longitudinal residual stress at the substrate side was within $-17 \mathrm{MPa} \sim 38 \mathrm{MPa}$ and at the cladding side was within $-40 \mathrm{MPa} \sim 48 \mathrm{MPa}$. The stress at the cladding side was greater than the stress at the substrate side, because the yield strength of the cladding plate wasgreater than the yield strength of the substrate.
Since the tail of clad plate generated swing pendulum vibration passing in and out the leveler, the residual stress showed larger fluctuations and risings. Fig. (7) shows that the longitudinal residual stress was well distributed along the width direction, the substrate and the cladding sides were observed to be symmetrical, and stress values increased largely near the edge.

\section{CONCLUSION}

The isothermal residual curvature straightening process wasproposed. The intermesh of No.2 and No.4 roller should be increased to make the plastic deformation ratio close to the limit value, which can eliminate the initial residual curvature. By setting large intermesh amount for No.10 roller, residual curvature bending to the side of base plate after straightening was ensured. As a result, the shape of stainless steel clad plate was observed to be satisfactory at room temperature after straightening, and the residual stress value was small and evenly distributed.

For different types of stainless steel clad plate straightening, by analyzing the straightening velocity and original curvature by FEM analysis, longitudinal residual stress distribution after straightening can be predicted. Effective process parameters setting can reduce the longitudinal residual stress of stainless steel clad plate and obtain excellent flatness.

\section{CONFLICT OF INTEREST}

The authors confirm that this article content has no conflict of interest.

\section{ACKNOWLEDGEMENTS}

This study is supported by Natural Science Foundation of Steel and Iron Foundation of Hebei Province of China (grant no. E2014203118).

\section{REFERENCES}

[1] M. N. Yang, X. Q. Zuo, and K. P. Wong, " Research progress of manufacturing technology for stainless steel clad plate," Mater. \& Heat Treat., vol. 41, no. 20, pp. 43-47, 2013.

[2] W. Yu, R. Espinola, Y. M. Zhang, and C. Y. He, et al. "Production of heavy-gauge steel plates by clad rolling process," Univ. Sci. Technol. B., vol. 33, no. 11, pp. 1391-1395, 2011.

[3] Y. Y. Wang, "Longitudinal buckle of asymmetric cladded stainless steel plates for hot rolling," Iron Steel Res. Int., vol. 5, no. 2, pp. 17-23, 1993.

[4] F. Cui, Straightening and straightening machine, Beijing: Metallurgical Industry Press, 2007, pp. 157-196.

[5] F. Kosel, T. Videnic, T. Kosel, and M. Brojan, "Elasto plastic springback of beams subjected to repeated bending/unbending histories", Mater. Eng. Perform, vol. 20, no. 6, pp. 846-854, 2011.

[6] E. Doege, and R. Menz, S. Huinink, "Analysis of the leveling process based upon an analytic forming model", Ann. CIRP, vol. 51, no. 1, pp. 191-194, 2002.

[7] C-L. Zhou, J. Xu, G-D. Wang, and X-H. Liu, "Intermesh model of hot roller leveler for plate steel", Iron Steel. Res. Int., vol. 18, no. 8, pp. 28-31, 2002.

[8] B. Y. Gong, Z. G. Wang, and Y. R. Lee, "Finite element analysis for the residual stress of plate during straightening process", Plast. Eng., vol. 17, no. 6, pp. 116-120, 2006.

[9] C. L. Zhou, G. D. Wang, and X. H. Liu, "The FEM analysis for the effect of intermesh to plate leveling deformation", Plast. Eng., vol. 13, no. 1, pp. 78-81, 2006 
[10] H. Huh, H. W. Lee, S. R. Park, G. Y. Kim, and S. H. Nam, "The Parametric process design of tension leveling with an elasto-plastic finite element method", Mater. Process. Tech., vol. 113, no. 1, pp. 714-719, 2001.
G-M. Xie, Z-A. Luo, G-L. Wang, and G-D. Wang, "Microstructure and properties of stainless steel clad plate by vacuum rolling cladding", Nor. Eas. Univ. (Nat. Sci.), vol. 32, no. 10, pp. 13981401, 2011.

(C) He-Rong et al.; Licensee Bentham Open

This is an open access article licensed under the terms of the Creative Commons Attribution Non-Commercial License (http://creativecommons.org/licenses/by-nc/4.0/) which permits unrestricted, non-commercial use, distribution and reproduction in any medium, provided the work is properly cited. 